\title{
A Note on The Rendering of Arabic Words and Phrases
}

Arabic words and phrases in this study have been rendered in the simplest manner yet recognizable to the Arabic speaker. Diacritical marks have been avoided wherever possible. Only the 'ain, the ba, and the internal glottal stop (by an umlaut) have been used. Place and tribal names and the names of my informants have been written in the French fashion currently in use in Morocco. Other words have been written in a manner more in keeping with English phonetics or as they appear in the Merriam-Webster Third New International Dictionary. With the exception of a few plurals such as "jnun," "foqra," and "ghiyyata," which occur frequently in the text, all other plurals of Arabic words are indicated by adding an " $s$ " to the singular form. Italics are generally used only on the first occurrence of a foreign word in each of its contexts. A glossary appears at the end of the study.

The reader will be able to approximate Moroccan Arabic pronunciation by pronouncing consonants as in English and vowels as in Italian. The $g$ is always hard as in "go" or "geese." The $j$ is pronounced like the " $\mathrm{s}$ " in "pleasure." The $q$ is like an English " $\mathrm{k}$ " but much further back in the throat. The $g h$ is pronounced like the uvular " $r$ " in French. The $k b$ is like the German "ch" in "Bach." The sh is like the "sh" in "ship." c and $b$ have no English or European equivalents. The ${ }^{c}$ is pronounced a little like "a" in father; $b$, like an " $h$ " in a loud stage whisper. The glottal stop indicates a break between vowels as in "uh oh."

In the pronunciation of place names the reader has only to remember that an initial ou is pronounced like a "w" and a $c b$ like an "sh." The final $e$ is not pronounced. 
And they cried aloud, and cut

themselves after their manner

with knives and lancets, till

the blood gushed out upon them.

(1 Kings 18, xxviii) 